\title{
PREVALENSI OBESITAS SENTRAL BERDASARKAN LINGKAR PINGGANG PADA PENGEMUDI BUS ANTAR KOTA
}

\author{
Frisca $^{1}$, Idawati Karjadidjaja ${ }^{2}$, Alexander Halim Santoso ${ }^{3}$ \\ ${ }^{1}$ Bagian Ilmu Gizi, Fakultas Kedokteran, Universitas Tarumanagara \\ Email:frisca@fk.untar.ac.id \\ ${ }^{2}$ Bagian Ilmu Gizi, Fakultas Kedokteran, Universitas Tarumanagara \\ Email: idawati.k@gmail.com \\ ${ }^{3}$ Bagian Ilmu Gizi, Fakultas Kedokteran Universitas Tarumanagara \\ Email:alexanders@fk.untar.ac.id
}

Masuk: 08-05-2019, revisi: 08-11-2019, diterima untuk diterbitkan: 18-11-2019

\begin{abstract}
ABSTRAK
Obesitas sentral telah menjadi masalah kesehatan masyarakat yang saat ini sangat meningkat pesat di seluruh dunia, termasuk di negara berkembang seperti Indonesia. World Health Organization menyatakan bahwa obesitas sentral merupakan faktor risiko utama terjadinya berbagai penyakit kardiometabolik, seperti diabetes dan hipertensi. Pengemudi bus antar kota merupakan pekerjaan dengan risiko tinggi terkena penyakit kardiometabolik tersebut, hal ini disebabkan karena gaya hidup dan pola kerja yang tidak sehat seperti tingginya konsumsi makanan berlemak, kebiasaan merokok, kurangnya aktivitas fisik, durasi menyetir yang lama dan pola tidur yang tidak teratur. Penelitian ini bertujuan untuk mengetahui prevalensi obesitas sentral berdasarkan lingkar pinggang pada pengemudi bus antar kota. Penelitian ini merupakan penelitian deskriptif dengan desain potong lintang. Data diperoleh dari pengukuran berat badan, tinggi badan dan lingkar pinggang, serta perhitungan indeks massa tubuh (IMT) pada 176 subjek yang diperoleh melalui metode consecutive sampling. Dikatakan Obesitas jika IMT $\geq 25$ menurut kriteria WHO untuk Asia-Pasifik dan obesitas sentral jika lingkar pinggang $>90 \mathrm{~cm}$ untuk laki-laki dan $>80$ $\mathrm{cm}$ untuk perempuan. Pada penelitian ini semua subjek adalah laki-laki dengan usia rata-rata 42.45 \pm 10.50 tahun. Berdasarkan perhitungan IMT terdapat $54.3 \%$ subjek mengalami obesitas. Melalui pengukuran lingkar pinggang terdapat $50.6 \%$ subjek dengan obesitas sentral. Pemberian edukasi sangat penting agar subjek dapat melakukan perubahan gaya hidup menjadi lebih baik sehingga dapat mencegah terjadinya penyakit kardiometabolik pada pengemudi bus antar kota.
\end{abstract}

Kata Kunci: obesitas sentral; lingkar pinggang; pengemudi bus

\section{ABSTRACT}

Central obesity has become a public health problem which is currently rapidly increasing throughout the world, including in developing countries like Indonesia. The World Health Organization states that central obesity is a major risk factor for various cardiometabolic diseases, such as diabetes and hypertension. Inter-city bus drivers are high-risk occupations of cardiometabolic disease, this is due to unhealthy lifestyles and work patterns such as high consumption of fatty foods, smoking habits, lack of physical activity, long driving times and irregular sleep patterns. This study aims to determine the prevalence of central obesity based on waist circumference in inter-city bus drivers. This research is a descriptive cross sectional study. Data obtained from measurements of body weight, height and waist circumference, as well as calculation of body mass index (BMI) on 176 subjects obtained through consecutive sampling method. Obesity is said if BMI $\geq 25$ according to WHO criteria for Asia-Pacific and central obesity if waist circumference $>90 \mathrm{~cm}$ for men and $>80 \mathrm{~cm}$ for women. In this study all subjects were men with an average age of $42.45 \square 10.50$ years. Based on the calculation of BMI there are $54.3 \%$ of subjects obese. Through measurement of waist circumference there are 50.6\% of subjects with central obesity. Providing education is very important so that subjects can make lifestyle changes for the better so as to prevent cardiometabolic disease in inter-city bus drivers.

Keywords: central obesity; waist size; bus driver 


\section{PENDAHULUAN}

Obesitas sentral adalah keadaan dimana terjadi akumulasi lemak di area abdominal yang ditandai dengan peningkatan ukuran lingkar pinggang. Dikatakan obesitas sentral jika lingkar pinggang $>90 \mathrm{~cm}$ untuk laki-laki dan $>80 \mathrm{~cm}$ untuk perempuan (McNeely, 2001). Obesitas sentral merupakan masalah kesehatan masyarakat yang saat ini sangat meningkat pesat di seluruh dunia. Prevalensi obesitas sentral di negara maju seperti Amerika Serikat mengalami peningkatan dari 46\% pada tahun 1999-2000 menjadi 57\% pada tahun 2013-2014. Di Asia seperti Cina prevalensinya 16,1 persen pada laki-laki dan 37,6 persen pada perempuan (CDC, 2016). Di Indonesia, prevalensi obesitas sentral penduduk umur $\geq 15$ tahun pada tahun 2013 adalah 26,6 persen, lebih tinggi dari prevalensi pada tahun 2007 (18,8\%) (RI, 2013). Pada tahun 2018, didapatkan prevalensinya meningkat lagi menjadi $31 \%$ dengan prevalensi terbanyak di DKI Jakarta dan Sulawesi Utara (RI, 2018)

Obesitas sentral dapat terjadi karena adanya perubahan gaya hidup seperti asupan makanan yang tinggi lemak, konsumsi sayuran dan buah yang kurang, konsumsi minuman yang mengandung alkohol, kebiasaan merokok dan aktivitas fisik yang kurang. Selain itu, peningkatan usia, perbedaan jenis kelamin, dan status sosio-ekonomi diduga juga berhubungan dengan kejadian obesitas sentral. World Health Organization (WHO) menyatakan bahwa peningkatan prevalensi obesitas sentral berdampak pada munculnya berbagai penyakit kardiometabolik seperti aterosklerosis, penyakit kardiovaskuler, diabetes tipe-2, batu empedu, gangguan fungsi pulmonal, hipertensi dan dislipidemia (Prentice, 2006).

Pengemudi bus antar kota merupakan pekerjaan dengan risiko tinggi terkena penyakit kardiometabolik, hal ini disebabkan karena gaya hidup dan pola kerja yang tidak sehat seperti tingginya konsumsi makanan berlemak, durasi menyetir yang lama dan pola tidur yang tidak teratur (Taklikar, 2016). Waktu kerja yang panjang sebagai pengemudi bus dapat menyebabkan perilaku yang menetap, yaitu kurangnya aktifitas dan pola makan yang buruk, yang berkontribusi pada risiko terjadinya obesitas dan obesitas sentral (Rosso, 2015). Penelitian yang telah dilakukan oleh Escoto dkk. melaporkan terjadinya peningkatan indeks massa tubuh pada pengemudi bus dengan waktu kerja yang panjang dan durasi tidur yang pendek (Escoto, 2010). Pada penelitian oleh Rosso dkk. pada sopir profesional di Italia diketahui $61 \%$ sopir mengalami overweight dan obesitas (Rosso, 2015). Berdasarkan studi Framingham diketahui bahwa peningkatan lingkar pinggang merupakan prediktor penyakit kardiometabolik yang lebih baik dibanding indeks massa tubuh (Chang, 2018). Oleh karena itu, penelitian ini bertujuan untuk mengetahui prevalensi obesitas sentral berdasarkan lingkar pinggang pada pengemudi bus antar kota.

\section{METODE PENELITIAN}

Penelitian ini merupakan penelitian deskriptif dengan desain potong lintang. Penelitian dilakukan pada 176 subyek yang diperoleh melalui metode consecutive sampling. Subjek penelitian adalah pengemudi bus antar kota di perusahaan bus GM. Subjek diberi penjelasan mengenai penelitian yang akan dilakukan dan diminta untuk menandatangani informed consent jika bersedia mengikuti penelitian. Pengumpulan data dilakukan dengan melakukan pengukuran berat badan (BB), tinggi badan (TB) dan lingkar pinggang (LP). Setiap pengukuran dilakukan sebanyak dua kali dan data yang diambil merupakan rata-rata dari hasil pengukuran tersebut. Hasil pengukuran BB dan TB digunakan untuk menghitung indeks massa tubuh.

Pengukuran BB dilakukan menggunakan timbangan BB Seca dengan ketelitian 0,1 kg yang ditempatkan di tempat yang keras dan permukaan yang rata. Subjek ditimbang dalam keadaan 
kandung kencing kosong dan sebelum makan. Subjek berdiri di tengah permukaan timbangan dan melihat lurus ke depan, berdiri tegak tanpa dibantu, tenang, memakai baju seringan mungkin, dan tanpa alas kaki atau kaos kaki.

Pengukuran TB dilakukan menggunakan microtoise stature dengan ketelitian $0,1 \mathrm{~cm}$ yang digantungkan pada dinding setinggi dua meter dari lantai dengan satuan sentimeter tepat di posisi angka nol. Pada waktu pengukuran, subjek tanpa alas kaki berdiri pada permukaan datar dan tumit merapat, kepala tegak menempel pada dinding sehingga pandangan tegak lurus dengan sumbu tubuh (Frankfurt plane). Bahu relaks dan kedua tangan tergantung bebas di sisi tubuh. Punggung, bokong, dan tumit menempel pada dinding. Kedua kaki lurus, kedua lutut merapat. Papan microtoise diturunkan sampai menyentuh bagian paling atas (verteks) kepala dan rambut tertekan.

Pengukuran lingkar pinggang dilakukan dengan menggunakan alat ukur SECA 201. Subjek berdiri tegak, kedua lengan tergantung di sisi tubuh, perut rileks, kedua kaki rapat, dan tidak menggunakan alas kaki. Pengukur menandai bagian tubuh yang mau diperiksa yaitu antara bagian bawah dari arcus costae dengan bagian atas crista iliaca pada garis mid-aksilaris. Pengukur melingkari pinggang subjek dengan pita pengukur sejajar pada bagian yang sudah ditandai.Pengukuran dilakukan 2 kali, dengan hasil pengukuran tidak berbeda $0,1 \mathrm{~cm}$. Data karakteristik diolah menggunakan program Statistical Program for Social Science (SPSS) versi 25 dan disajikan dalam bentuk n (\%).

\section{HASIL DAN PEMBAHASAN Karakteristik Subjek}

Subjek yang mengikuti penelitian ini terdiri dari 176 orang pengemudi bus antar kota. Semua subjek dalam penelitian ini adalah laki-laki yang berusia mulai dari 21 tahun sampai 61 tahun dengan usia rata-rata adalah 41,71 $\pm 8,18$ tahun. Dari 176 subjek yang diteliti, didapatkan 54\% subjek mempunyai status gizi obesitas berdasarkan kriteria WHO untuk penduduk Asia. Berdasarkan Indeks Massa Tubuh (IMT), obesitas dibagi menjadi dua kategori, yaitu obesitas I dan obesitas II. Untuk penduduk Barat, seseorang dikatakan obesitas apabila IMT $\geq 30$, sedangkan untuk penduduk Asia bila IMT $\geq 25$ (Kanazawa, 2005). Sebaran karakteristik subjek berdasarkan usia dan status gizi berdasarkan IMT dapat dilihat pada tabel 1.

Hasil pada penelitian ini sesuai dengan beberapa penelitian, diantaranya adalah penelitian oleh Asif dkk. yang melaporkan bahwa terdapat 51,3 persen subjek dengan status gizi overweight dan obesitas berdasarkan kriteria untuk penduduk Barat (Asif, 2017). Hasil penelitian tersebut menunjukkan bahwa mayoritas $(72,75 \%)$ subjek penelitian bekerja 7 jam atau lebih dalam sehari dan didapatkan proporsi overweight dan obesitas yang lebih tinggi dibandingkan subjek yang durasi kerjanya 6 jam atau kurang. Penelitian Rosso dkk. melaporkan prevalensi obesitas yang lebih tinggi sebesar $61 \%$ pada pengemudi bus dan dilaporkan bahwa jam kerja yang panjang dikaitkan dengan massa tubuh yang lebih tinggi (Rosso, 2015). Lorenzo dkk. melaporkan bahwa IMT secara signifikan lebih besar di antara pekerja shift bergilir dibandingkan dengan pekerja harian dengan waktu kerja yang tetap (Lorenzo, 2003).

Perbedaan dalam tingkat prevalensi yang disebutkan dalam beberapa studi di atas dapat disebabkan oleh perbedaan dalam kelompok umur yang diteliti, adanya jenis kelamin perempuan dalam beberapa penelitian, dan perbedaan dalam lingkungan kehidupan. Status gizi pengemudi 
yang obesitas ini selain dipengaruhi oleh pola kerja yang kurang baik, juga disebabkan oleh asupan makanan yang tinggi kalori dan lemak serta pola hidup sedenteri dengan aktivitas fisik yang kurang.

Tabel 1. Sebaran karakteristik subjek berdasarkan usia, jenis kelamin, dan status gizi berdasarkan IMT

\begin{tabular}{lc}
\hline Variabel & Nilai \\
\hline Usia, tahun & 41,$71 ; 8,18$ \\
Berat badan, kg & 71,$96 ; 13,26$ \\
Tinggi badan, cm & 165,$97 ; 14,42$ \\
Indeks massa tubuh, kg/m² & 25,$86 ; 3,36$ \\
Klasifikasi IMT, n (\%) & \\
Berat badan kurang & $11(6,3)$ \\
Normal & $40(22,7)$ \\
Berat badan lebih & $30(17)$ \\
Obesitas I & $64(36,4)$ \\
Obesitas II & $31(17,6)$
\end{tabular}

*mean;SD

\section{Obesitas Sentral}

Lingkar pinggang merupakan alat ukur distribusi lemak abdominal dimana peningkatan lingkar pinggang merupakan prediktor sindroma metabolik yang lebih baik dibandingkan dengan IMT. Dalam penelitian ini, klasifikasi lingkar pinggang dibagi menjadi 2 kelompok yaitu obesitas sentral jika LP $>90 \mathrm{~cm}$ dan tidak obesitas sentral jika LP $\leq 90 \mathrm{~cm}$. Tabel 2 menunjukkan sebaran obesitas sentral berdasarkan linggar pinggang subjek penelitian. Didapatkan sebanyak 51,7\% subjek menderita obesitas sentral karena memiliki lingkar pinggang di atas $90 \mathrm{~cm}$.

Hasil ini lebih rendah dibandingkan dengan beberapa penelitian, diantaranya adalah oleh Sangaleti dkk. (2014) yang dilakukan pada pengemudi truk didapatkan prevalensi obesitas sentral sebesar 58,2\% dan penelitian oleh Saberi dkk. (2011) yang dilakukan pada pengemudi bus di Kashan, Iran didapatkan prevalensi obesitas sentral sebesar 68,3\%. Walaupun lebih rendah dari studi-studi lain, namun prevalensi obesitas sentral sebesar $51,7 \%$ pada penelitian ini cukup tinggi, menunjukkan bahwa lebih dari separuh dari total subjek mempunyai risiko untuk menderita penyakit kardiometabolik.

Tabel 2. Sebaran obesitas sentral berdasarkan lingkar pinggang subjek

\begin{tabular}{lc}
\hline Variabel & Nilai \\
\hline Lingkar pinggang, cm & \\
Klasifikasi obesitas sentral \\
berdasarkan lingkar pinggang, \\
$\mathrm{n}(\%) \quad$ Obesitas sentral & 90,$56 ; 13,85$ \\
$\quad$ Tidak obesitas sentral & $91(51,7)$ \\
\hline
\end{tabular}

*mean;SD 
Pada penelitian ini didapatkan subjek yang menderita obesitas berdasarkan IMT lebih banyak yaitu sebesar 54\%, sedangkan subjek yang menderita obesitas sentral berdasarkan lingkar pinggang sebesar 51,7\%. Hasil ini sesuai dengan hasil penelitian oleh Pasumbung dkk. (2015) yang melaporkan bahwa skrining obesitas pada subjek berdasarkan IMT dan LP didapatkan perbedaan hasil yang cukup besar dimana didapatkan jumlah subjek yang menderita obesitas berdasarkan IMT lebih banyak dibanding skrining obesitas berdasarkan LP.

Tabel 3. Sebaran status obesitas sentral dan status gizi subjek

\begin{tabular}{lcc}
\hline \multicolumn{1}{c}{ Status gizi } & \multicolumn{2}{c}{ Status obesitas sentral } \\
\cline { 2 - 3 } & $\begin{array}{c}\text { Obesitas sentral } \\
\mathrm{n}(\%)\end{array}$ & $\begin{array}{c}\text { Tidak obesitas } \\
\text { sentral } \\
\mathrm{n}(\%)\end{array}$ \\
\hline Berat badan & $0(0)$ & $11(12,9)$ \\
kurang & $2(2,2)$ & $38(44,7)$ \\
Normal & $7(7,7)$ & $23(27,1)$ \\
Berat badan lebih & $53(58,2)$ & $11(12,9)$ \\
Obesitas 1 & $29(31,9)$ & $2(2,4)$ \\
Obesitas 2 & & \\
\hline
\end{tabular}

Berdasarkan tabel 3 diketahui bahwa dari 95 subjek dengan IMT $\geq 25$ didapatkan 82 (86,3\%) subjek mempunyai lingkar pinggang yang lebih besar dari normal. Hal ini menunjukan dari 95 subjek yang obesitas berdasarkan IMT terdapat $86,3 \%$ subjek yang berisiko menderita penyakit kardiometabolik. Berdasarkan tabel 3 juga dapat diketahui bahwa semakin besar IMT subjek, semakin meningkat juga risiko terjadi obesitas sentral.

\section{KESIMPULAN DAN SARAN}

\section{Kesimpulan}

Berdasarkan hasil pemeriksaan antropometri yaitu berat badan dan tinggi badan ditemukan lebih dari setengah dari jumlah pengemudi di suatu perusahaan bus antar kota mengalami obesitas. Untuk mengetahui risiko terhadap penyakit kardiometabolik, pengemudi juga diukur lingkar pinggangnya dan didapatkan hasil bahwa terdapat $51,7 \%$ pengemudi bus yang menderita obesitas sentral. Pada penelitian ini terlihat bahwa semakin besar indeks massa tubuh subjek maka semakin meningkat juga risiko terjadi obesitas sentral.

\section{Saran}

Pengamatan ini hanya dilakukan pada satu perusahaan bus antar kota, oleh karena itu perlu dilakukan penelitian lebih lanjut pada jumlah subjek yang lebih besar. Disamping itu perlu diteliti lebih dalam untuk mengetahui faktor-faktor apa saja yang berperan terhadap obesitas sentral pada pengemudi bus antar kota, sehingga dapat dilakukan edukasi agar subjek dapat melakukan perubahan gaya hidup menjadi lebih baik. 


\section{REFERENSI}

Asif, M; Aslam, M; Altaf, S. (2017). Long Working Hours and Short Sleep Associated with Obesity among Professional Drivers and Conductors. ANNALS; 23: 145-151

CDC. (2016). Prevalence of overweight and obesity in the general adult population. Dikutip 15 April 2019 dari Centers for Disease Control and Prevention. Website : https://nccd.cdc.gov/ckd/detail.aspx?Qnum=Q146

Chang, KT; Chen, CH; Chuang, HH; Tsao, YC; Lin, YA; Lin, P. (2018). Which obesity index is the best predictor for high cardiovascular disease risk in middle-aged and elderly population?. Archives of Gerontology and Geriatrics; 78:165-170

Escoto, K; French, S; Harnack, LJ; Toomey, TL; Hannan, PJ; Mitchell, NR. (2010). Work hours, weight status, and weight-related behaviors: a study of metro transit workers. Int J Behav Nutr Phys Act; 7: 91.

Kanazawa, M; Yoshiike, N; Osaka, T; Numba, Y; Zimmet, P; Inoue, S. (2005). Criteria and classification of obesity in Japan and Asia-Oceania. World Rev Nutr Diet ;94:1-12

Lorenzo, LD; Pergola, GD; Zocchetti, C; L'Abbate, N; Basso, A; Pannacciulli, N. (2003). Effect of shift work on body mass index: results of a study performed in 319 glucose-tolerant men working in a Southern Italian industry. International Journal of Obesity; 27: 1353-1358

McNeely, MJ; Boyko, EJ; Shofer, JB; Newell-Morris, L; Leonetti, DL; Fujimoto, WY. (2001), Standard definitions of overweight and central adiposity for determining diabetes risk in Japanese Americans. Am J Clin Nutr ;74(1):101-7

Pasumbung, E; Purba, MM. (2015). Faktor risiko obesitas berdasarkan indeks massa tubuh dan lingkar pinggang di sma katolik palangkaraya. jurnal vokasi kesehatan; 1:1 - 8

Prentice, AM. (2006). The emerging epidemic of obesity in developing countries. Int $J$ Epidemiol.,35(1):93-9.

RI, Badan Penelitian dan Pengembangan Kesehatan Kementerian Kesehatan. (2013). Riset Kesehatan Dasar (Riskesdas) 2013

RI, Badan Penelitian dan Pengembangan Kesehatan Kementerian Kesehatan. (2018). Riset Kesehatan Dasar (Riskesdas) 2018

Rosso, GL; Perotto, M; Feola, M; Bruno, G; Caramella, M. (2015). Investigating obesity among professional drivers: The High Risk Professional Driver Study. Am J Ind Med ;58(2):2129.

Saberi, HR; Moravveji, AR; Fakharian, E; Kashani, MM; Dehdashti, AR. (2011). Prevalence of metabolic syndrome in bus and truck drivers in Kashan, Iran. Diabetol Metab Syndr ; 3: 8.

Sangaleti, CT; Trincaus, MR; Baratieri, T; Zarowy, K; Ladika, MB; Menon, MU. (2014). Prevalence of cardiovascular risk factors among truck drivers in the South of Brazil. BMC Public Health ; 14:1063.

Taklikar, C. S. (2016). Occupational stress and its associated health disorders among bus drivers. Int J Community Med Public Health.,3(1):208-211 